\title{
Author Correction: Roles and regulation of histone methylation in animal development
}

Ashwini Jambhekar(iD, Abhinav Dhall and Yang Shi

Nature Reviews Molecular Cell Biology 20, 625-641 (2019) https://doi.org/10.1038/s41580-019-0151-1 Published online 02 July 2019

In the original article, BMI1 - a member of the PRC1 complex - was incorrectly assigned as a PRC2 component. This has been addressed through editing relevant parts of the article on pages 631 and 634, and in Table 1. The mistake has been corrected in the HTML and PDF versions of the article.

https://doi.org/10.1038/s41580-019-0192-5 I Published online 7 November 2019 